\title{
Expression Profile of TNF- $\alpha$ among Impaired Glucose Tolerant and Type 2 Diabetic Subjects in Relation with Vascular Inflammation
}

\author{
Rehana Shahida $^{1}$, Tasnim Farasat ${ }^{1}$, Shagufta Naz $^{1, *}$ and Shahjahan ${ }^{2}$ \\ ${ }^{1}$ Department of Zoology, Lahore College for Women University, Jail Road, Lahore \\ ${ }^{2}$ Department of Immunology, University of Health Sciences, Lahore
}

\begin{abstract}
A B S T R A C T
The present study aims to study the expression of TNF- $\alpha$ among impaired glucose tolerant $(n=35)$, diabetic subjects (n-35) and age matched healthy control $(n=35)$, and to identify the relationship of inflammatory cytokines with insulin resistance and the molecular mechanisms involved in the interaction of atherosclerosis and hyperglycemia within the context of chosen pro atherogenic parameters including plasma glucose level, serum levels of insulin, IL-6, and TNF- $\alpha$. Serum level of thrombomodulin was assessed as a measure of vascular damage. Different demographic parameters as age, BMI, waist / hip ratio, B.P., personal history and socioeconomic status were recorded. Fasting glucose and HbA1c was done by chemistry analyzer. Fasting serum insulin, IL-6, TNF- $\alpha$ and thrombomodulin levels were assessed by ELIZA. Gene expression was measured by RT-PCR. Insulin resistance was calculated by HOMA-IR. TNF- $\alpha$ and IL-6 levels were high in IGT and diabetic group as compared to control. ANOVA revealed highly significant difference of mean among groups and between groups in IL-6, TNF- $\alpha$, and thrombomodulin $(\mathrm{P}<0.01)$.TNF- $\alpha$ showed a strong and positive relationship with insulin and insulin resistance in all the three groups. The expression level of TNF- $\alpha$ was significantly higher in IGT $\mathrm{p}<$ 0.01 and diabetes subjects $(\mathrm{p}<0.01)$. It was 2.44 fold higher in IGT group and 4.5 fold higher in diabetic group. Expression levels significantly correlated with serum values of TNF- $\alpha(p<0.01)$. Thrombomodulin showed a strong relationship with insulin and insulin resistance in diabetic group $(\mathrm{p}<0.05)$.
\end{abstract}

\begin{tabular}{l} 
Article Information \\
Received 22 October 2016 \\
Revised 03 March 2017 \\
Accepted 25 May 2017 \\
Available online 15 November 2017 \\
Authors' Contribution \\
This article is a part of thesis \\
of RS who planned and did \\
experimental work. TF conceived \\
the idea,supervised in experimental \\
design, writing and analysis of data. \\
SN co-supervised experimental work, \\
primer designing and methodology. \\
Shahjahan co supervised experimental \\
work and data analysis. \\
Key words \\
\hline TNF- $\alpha$, TNF- $\alpha$ expression, Impaired \\
glucose tolerant, Type 2 diabetic \\
subjects, Vascular inflammation.
\end{tabular}

\section{INTRODUCTION}

$\mathrm{T}$ umor necrosis factor- $\alpha(\mathrm{TNF}-\alpha)$ has been found to play a critical role in diabetes associated atherosclerosis. It also affects the insulin signaling pathways and causes insulin resistance (Curtis et al., 2014). Peripheral blood mononuclear cells (PBMC) are activated in hyperglycemia and release pro-inflammatory cytokines such as TNF- $\alpha$ and IL-6. Different studies have identified IL-6 as an inflammatory cytokine which play a key role in the propagation of inflammatory reactions responsible for atherosclerosis (Hartman and Frishman, 2014). IL-6 can reduce insulin signaling sensitivity by eliciting different important steps in the insulin pathways. Thrombomodulin (TM) is a marker which indicates endothelial injury (Michael et al., 2002; Ohlin et al., 2005). The exact mechanism underlying the impaired vascular activity remains unresolved and there is no scientific consensus for these pathophysiological conditions (Zhang et al., 2009). Currently there are increasing evidences that

\footnotetext{
Corresponding author: shagufta6@gmail.com 0030-9923/2017/0006-2153 \$ 9.00/0

Copyright 2017 Zoological Society of Pakistan
}

proatherogenic effect of diabetes is mediated through inflammatory mechanism (Williams and Nadler, 2007). This may open the new avenues to search for the therapeutic targets for these medical problems. Activation of monocytes during early stages of atherosclerosis results in the release of TNF-alpha, a mediator of inflammation (Mangge et al., 2004; Gacka et al., 2010). Thrombomodulin (TM) is a marker which indicates the endothelial injury. It is a glycoprotein expressed on the endothelial cell surface of various tissues. Various soluble TM fragments are found in plasma at higher concentrations in different diseases such as inflammatory endothelial injuries, diabetes and cardiovascular disease (Michael et al., 2002; Ohlin et al., 2005).

It has been documented that levels of inflammatory cytokine, TNF- $\alpha$ and IL- 6 have a linear and positive relationship with blood glucose level in development of atherosclerosis and plaque formation (Mirza et al., 2012).

The present study was undertaken to assess the serum concentration of TNF- $\alpha$ and messenger RNA expression level in peripheral blood mononuclear cells (PBMC) of impaired glucose tolerance patients and the patients of diabetes, and find its relationship with other clinical parameters of diabetes. 


\section{MATERIALS AND METHODS}

Blood samples $(6 \mathrm{ml})$ of 35 IGT patients and 35 diabetic subjects were drawn after overnight fast of 12 hours. Their nutritional and physical activity status was also taken into consideration. Patients of IGT and newly Diagnosed Type 2 diabetes of 40-60 years of age were selected after oral glucose tolerance test. The control group consisted of 35 healthy volunteers of the same age group. All the subjects taking insulin or any kind of medication related to diabetes were excluded from the study. The drawn blood was separated into two portions. One portion of $3 \mathrm{ml}$ was used for serum separation. The separated serum was stored at $-20^{\circ} \mathrm{C}$ for further biochemical analysis.

The other portion was used for PBMC isolation to study the gene expression profile of TNF- $\alpha$. Fasting glucose levels and $\mathrm{HbA} 1 \mathrm{c}$ were assessed by the hospital's routine chemistry analyzer (Hitachi 902 Biochemical analyzer).

Serum was used to assess the base line levels of TNF- $\alpha$, IL- 6 , insulin and thrombomodulin in IGT, diabetic and control subjects. The base line levels of TNF- $\alpha$ and IL-6 were assessed by using Diaclone ELISA kits for TNF- $\alpha$ and IL-6, insulin by using Calbiotech insulin ELISA Kit and thrombomodulin by Glory Science TM ELISA Kit. Insulin resistance was calculated by applying formula:

HOMA-IR $=$ Fasting serum insulin $(\mu \mathrm{U} / \mathrm{ml}) \times$ Fasting plasma glucose / 22.5

PBMC were isolated for extraction of RNA. Isolated PBMC pellet was dissolved in $50 \mu$ l of the lyses solution until they were proceeded for RNA extraction. Then this was treated with $500 \mu 1$ trizole and $100 \mu 1$ of chloroform was added to it. The mixture was shaken for 2-5 times by hand to mix and centrifuged at $13,200 \mathrm{rpm}$ for $15 \mathrm{~min}$ at $4^{\circ} \mathrm{C}$. RNA, DNA and proteins were separated into layers. RNA layer was pippeted out into a clean $1.5 \mathrm{ml}$ tube containing $500 \mu 1 \quad 100 \%$ isopropanol and centrifuged at 13,200 rpm for $15 \mathrm{~min}$. RNA was visible as a small, translucent pellet. The supernatant was poured off and the tube was drained on clean absorbent paper. RNA pellet was given a wash with $70 \%$ ethanol, centrifuged at $13000 \mathrm{rpm}$ for $10 \mathrm{~min}$, poured off the ethanol, allowed to air dry. $20 \mu$ l of DEPC treated water was added to the RNA, incubated at room temperature for $10-15 \mathrm{~min}$ and then stored at $-20^{\circ} \mathrm{C}$ (Simms et al., 1993). Quantity and quality of RNA was measured by nanodrop at $260 \mathrm{~nm}$ and then cDNA was synthesized by using enzynomic kit for cDNA synthesis.

cDNA was used for PCR amplification of TNF- $\alpha$ and a house keeping gene GAPDH using the gene specific forward and reverse primers. PCR products were sequenced (Table I).
Table I.- Sequence of primers used in this study.

\begin{tabular}{llll}
\hline Gene & Primer & \multicolumn{2}{l}{$\begin{array}{l}\text { GC } \\
\text { content \% }\end{array}$} \\
\hline TNF $\alpha-\mathrm{F}$ & 5'AGTCAACTCTGCCTCCCTCA 3' & 50 & 232 \\
TNF $\alpha-\mathrm{R}$ & 5'TGATCCAATCCCAGCTTTTC 3' & 55 & \\
GAPDH-F & 5'ACCACAGTCCATGCCATCA 3' & 58 & 453 \\
GAPDH-R & 5 5'TCCACCACCCTGTTGCTGTA 3' & 56 & \\
\hline
\end{tabular}

Only exonic sequences were used for primer designing to avoid genomic DNA contamination. The sequences were placed into primer designing tool i.e. (www.primer3) for primer designing.

Gene expression analysis of TNF- $\alpha$ was done by using specific-primers of TNF- $\alpha$ gene on Applied Biosystem using Step One software v 2.1 on Real Time PCR. Master Mix of kit TOPrealTM q-PCR 2X premix (SYBR Green with low ROX) was used according to Manufacturer's instructions. The relative gene expression analysis was carried out by using SDS 3.1 software provided by ABI. Statistical analysis was done on SPSS, version 13.

\section{Statistical analysis}

Data is given as the mean \pm SEM. Differences in the means of variable were tested by both parametric and non-parametric tests, depending on the distribution of the variables. For normal distribution Pearson's correlation was used. Descriptive statistics were done for all variable including age and BMI. Correlation (bivariate) analysis was conducted using Pearson's or Spearman's correlation coefficients with $95 \%$ confidence interval. $\mathrm{P}<0.05$ (two tailed) was considered significant. Analysis of variance (ANOVA) was used to observe the difference among the groups. To find the significant difference between the two groups in a post hoc analysis Tukey test was applied. Stepwise linear regression models were used to investigate the determinants and predictors. The variables for which $\mathrm{p}$ value exceeded 0.05 , were eliminated in a stepwise fashion; so that only those that had a statistically significant association $(\mathrm{P}<0.05)$ were included in the final regression model. Analysis was performed by using software SPSS Version 13 (Statistical Package for Windows, SPSS, Chicago, IL, U.S.A.).

\section{RESULTS}

In this study, subjects $(\mathrm{n}=105)$ including control, IGT and diabetic group $(n=35)$ each were selected. Mean \pm SEM values of all anthropometric, biochemical characteristics, RQ and fold value of gene expression in control, IGT and diabetic group are presented in Table II. 
Table II.- Demographic and biochemical characteristics of control, IGT and diabetic subjects (Mean \pm SEM).

\begin{tabular}{lcccc}
\hline Name of variable & Control $(\mathbf{n}=\mathbf{3 5})$ & IGT $(\mathbf{n}=\mathbf{3 5})$ & Diabetic $(\mathbf{n}=\mathbf{3 5})$ & ANOVA $(\mathbf{p}$ value) \\
\hline Age $($ years $)$ & $47.96 \pm 0.74(40-60)$ & $49.85 \pm 0.75(40-60)$ & $48.77 \pm 0.64(40-60)$ & 0.178 \\
BMI & $26.77 \pm 0.39$ & $31.19 \pm 0.77^{1-2}$ & $30.69 \pm 0.59^{1-3}$ & $0.000^{*}$ \\
WHR & $0.86 \pm 0.01$ & $0.88 \pm 0.01$ & $0.89 \pm 0.01^{1-3}$ & $0.004^{* *}$ \\
BSF $(\mathrm{mg} / \mathrm{dl})$ & $82.66 \pm 0.08^{1-2}$ & $111.15 \pm 0.66^{2-3}$ & $183.17 \pm 4.43^{1-3}$ & $0.000^{* *}$ \\
HbAlc $(\%)$ & $5.07 \pm 0.03^{1-2}$ & $5.99 \pm 0.02^{2-3}$ & $9.77 \pm 0.23^{1-3}$ & $0.000^{* *}$ \\
Systolic BP $(\mathrm{mm} / \mathrm{Hg})$ & $120.35 \pm 0.81$ & $134.17 \pm 2.02^{1-2}$ & $134.38 \pm 1.73^{1-3}$ & $0.000^{* *}$ \\
Diastolic BP $(\mathrm{mm} / \mathrm{Hg})$ & $81.22 \pm 0.63$ & $88.88 \pm 1.15^{1-2}$ & $87.02 \pm 0.99^{1-3}$ & $0.000^{* *}$ \\
Insulin $(\mu \mathrm{IU} / \mathrm{ml})$ & $6.318 \pm 0.405$ & $20.182 \pm 2.64^{2-3}$ & $42.295 .534^{1-3}$ & $0.000^{* *}$ \\
Serum TNF- $\alpha(\mathrm{Pg} / \mathrm{ml})$ & $4.213 \pm 0.147^{1-2}$ & $22.1571 .137^{2-3}$ & $56.946 \pm 4.928^{2-3}$ & $0.000^{* *}$ \\
IL-6 (Pg/ml) & $1.36 \pm 0.04^{1-2}$ & $6.88 \pm 0.29^{2-3}$ & $10.99 \pm 0.841-3$ & $0.000^{* *}$ \\
Thrombomoduli $(\mu \mathrm{g} / \mathrm{L})$ & $3.586 \pm 0.180$ & $7.09 \pm 0.83^{2-3}$ & $26.83 \pm 2.05^{1-3}$ & $0.000^{* *}$ \\
RQ & $0.023 \pm 0.003$ & $0.032 \pm 0.0032-3$ & $0.075 \pm 0.001-3$ & $0.000^{* *}$ \\
Expression of mRNA (fold value) & 1 & $2.44 \pm 0.06$ & $4.5 \pm 0.05$ & $0.000^{* *}$ \\
HOMA IR & $1.293 \pm 0.09$ & $5.71 \pm 0.76_{2-3}$ & $21.89 \pm 3.62^{1-3}$ & $0.000^{* *}$ \\
\hline
\end{tabular}

**, $\mathrm{p}<0.001 ; 1-3$, control-diabetic; 2-3, IGT-diabetic.

Table III.- Correlation of RQ mean with TNF- $\alpha$,Thrombomodulin, Insulin and HOMA-IR in control, IGT and diabetic groups.

\begin{tabular}{|c|c|c|c|c|c|c|c|c|c|c|c|}
\hline \multirow[t]{2}{*}{ Variable } & \multirow[t]{2}{*}{ Group } & \multicolumn{2}{|c|}{ TNF- $\alpha$} & \multicolumn{2}{|c|}{ Thrombomodulin } & \multicolumn{2}{|c|}{ Insulin } & \multicolumn{2}{|c|}{ HOMA-IR } & \multicolumn{2}{|c|}{ IL-6 } \\
\hline & & $\Gamma$ & $\mathbf{P}$ & $\Gamma$ & $\mathbf{P}$ & $\Gamma$ & $\mathbf{P}$ & $\Gamma$ & $\mathbf{P}$ & $\Gamma$ & $\mathbf{P}$ \\
\hline \multirow[t]{3}{*}{ RQ } & Control $n=35$ & $0.791^{* *}$ & 0.000 & $0.409^{*}$ & 0.015 & $0.437^{* *}$ & 0.009 & $0.342^{*}$ & 0.044 & $0.522^{* *}$ & 0.000 \\
\hline & IGT $n=35$ & 0.7 .2 & 0.000 & -0.178 & 0.307 & $0 . .010$ & 0.954 & 0.026 & 0.883 & $0.272^{* *}$ & 0.007 \\
\hline & Diabetic $n=35$ & 0.603 & 0.000 & -0.064 & 0.713 & $0.349^{*}$ & 0.040 & $0.393^{*}$ & 0.020 & 0.103 & 0.300 \\
\hline
\end{tabular}

**Correlation is significant at 0.001 level (two tailed); *Correlation is significant at 0.01 level (two tailed).

Table IV.- Stepwise multiple regression analysis using TNF- $\alpha$ as dependent variable and other variables as independent variable in Control, IGT and diabetic group.

\begin{tabular}{lcccc}
\hline $\begin{array}{l}\text { Independent } \\
\text { variable }\end{array}$ & $\begin{array}{c}\boldsymbol{\beta} \text { coefficient } \\
\pm \text { SE }\end{array}$ & $\mathbf{T}$ & $\mathbf{P}$ value & Total $\mathbf{R}^{2}$ \\
\hline $\begin{array}{l}\text { Control group } \\
\text { IL-6 }\end{array}$ & $0.434 \pm 0.243$ & 5.083 & 0.000 & 0.273 \\
Thrombomodulin & $0.304 \pm 0.154$ & 3.562 & 0.001 & 0.358 \\
IGT group & & & & \\
HOMA-IR & $0.380 \pm 0.247$ & 3.979 & 0.000 & 0.144 \\
IL-6 & $0.209 \pm 0.373$ & 2.193 & 0.031 & 0.169 \\
Diabetic group & & & & \\
Insulin & $0.713 \pm 0.090$ & 10.279 & 0.000 & 0.509 \\
Thrombomodulin & $0.165 \pm 0.148$ & 2.496 & 0.014 & 0.585 \\
WHR & $0.231 \pm 0.159$ & 3.569 & 0.001 & 0.559 \\
\hline
\end{tabular}

Predictors, IL- 6 and thrombomodulin dependent variable TNF- $\alpha$.
Correlation of TNF- $\alpha$ gene expression was observed with the serum levels of TNF- $\alpha$, IL-6thrombomodulin, insulin and HOMA IR. The correlation results are presented in Table III. Expression level of TNF- $\alpha$ gene had a strong relationship with its serum level in all the three groups. A strong association of serum IL-6 was observed with RQ value of TNF- $\alpha$ in control and IGT group. Significant correlation was observed between expression of TNF- $\alpha$ and serum level of insulin in control and diabetic group. Similarly significant association of gene expression was seen with HOMA IR. Non-significant association of relative quantification (RQ) was observed with insulin and HOMA IR in IGT group. RQ of TNF- $\alpha$ had a significant correlation with thrombomodulin only in control group, IGT and diabetic group showed nonsignificant association. Results of regression analysis are given in Table IV. 


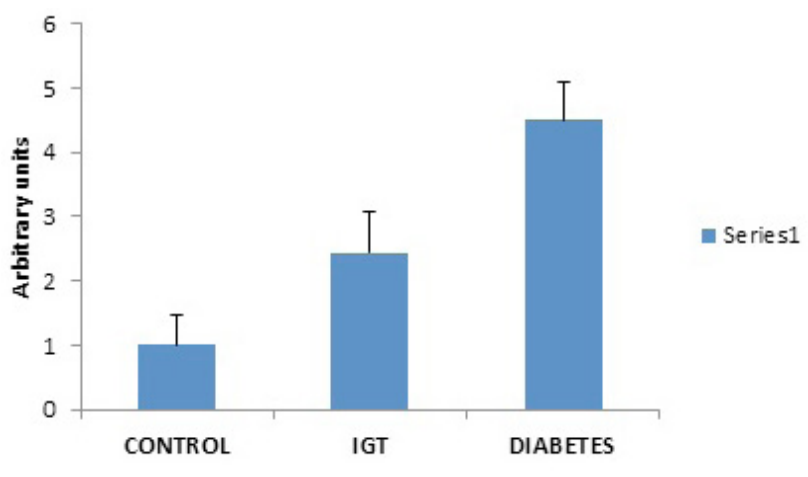

Fig. 1. Relative mRNA expression level of TNF- $\alpha$ in PBMCs of control, IGT and diabetic subjects.

\section{DISCUSSION}

There is now emerging the concept that diabetes is an inflammatory disease. The present study is conducted to assess expression of TNF-alpha gene in PBMC in IGT and newly diagnosed diabetic subjects in comparison to normal healthy subjects and its relationship with serum levels of IL-6, insulin, Insulin resistance and thrombomodulin. Our results show that subjects with impaired glucose tolerance and diabetes have elevated serum levels of TNF- $\alpha$ in comparison to healthy non-diabetic control subjects. Previous studies exhibited that hyperglycemia in diabetes is linked with elevated levels of inflammatory cytokines as TNF- $\alpha$ (Pickup et al., 2000; Tomelkava-Kurktschiev et al., 2002). According to Mishima et al. (2001) and Rajarajeswari et al. (2011), TNF- $\alpha$ levels are elevated in type 2 diabetes. Persuasive data in the literature has demonstrated that there are changes in the inflammation and redox balance in type 2 diabetes with elevation in systemic markers such as TNF- $\alpha$ and IL-6 (Deepa et al., 2006; Gokulakrishnan et al., 2009).

Our results show an increase in the mRNA expression of TNF-alpha gene in IGT and diabetic subjects. This higher expression of TNF-alpha gene in PBMCs might be responsible for the macrovascular disease in these subjects. In our study these cytokines show a linear positive relationship with blood glucose levels. The production of reactive oxygen species (ROS) can stimulate cytokine cascade through nuclear factor- kappa B (NF-kB), transcriptional factor which induces the the expression of TNF- $\alpha$ (De Martin et al., 2000; Ye et al., 2003). Mirza et al. (2012) has reported that TNF- $\alpha$ and IL-6 have a linear and positive relationship with blood glucose level in atherogenic process so study of Mirza support our results.

In this study the fasting levels of insulin were assessed and Insulin resistance was calculated to find the relationship of inflammatory marker TNF- $\alpha$ with insulin and insulin resistance. Values of both of these parameters were increased in IGT and diabetic group as compared to control group and TNF- $\alpha$ showed a significant correlation with insulin and insulin resistance. Some authors have demonstrated increased serum levels of TNF- $\alpha$ in type 2 DM and IGT subjects (Gupta et al., 2005; Cardellini et al., 2007; Hossain et al., 2010). Our findings are also consistent with these authors.

Insulin resistance is a central cause of common atherogenic diseases including obesity and type $2 \mathrm{DM}$ (Togashi et al., 2002). Many studies prove that TNF- $\alpha$ plays a central role in the insulin resistance (IR) resulting from an interaction with insulin signaling pathway. Thus IR has been recognized as a high risk n-factor for the development of type $2 \mathrm{DM}$ and cardiovascular disease (CVD) (Rajrajeshwari et al., 2011).

In stepwise multiple regression, IL-6 and thrombomodulin were significantly associated with TNF- $\alpha$ expression in control group while in IGT, IL-6 and HOMA IR were the predictors. In diabetic group insulin and thrombomodulin and WHR were significantly associated with the expression of TNF- $\alpha$.

Results of epidemiological studies suggest that in addition to TNF- $\alpha$ inflammatory marker IL-6 is also predictor of glucose disorder and development of diabetes (Schmidt et al., 1999). In in vitro studies it has been observed that in supraphysiological glucose concentrations, IL-6 and TNF- secretion is increased in human healthy mononuclear cells. Same results were observed in the placental tissue explants from women with gestational diabetes incubated with high glucose concentration (Morohoshi et al., 1996; Coughlan et al., 2001).

Insulin resistance is defined as the in sufficiency of insulin to promote glucose uptake in adipose tissue and skeletal muscle and to reduce hepatic glucose output. TNF- $\alpha$ is a potent inhibitor of the tyrosine kinase activity of the insulin receptors (IR) and the insulin receptor substrate-1 (IRS-1). It causes serine phosphorylation of IRS-1 and converting it into an inhibitor of the insulin receptor tyrosine kinase. Some previous studies are consistent with these findings (Hotamisligil and Spiegelman, 1994).

Patients of type 2 diabetes mellitus have higher waist circumference and waist hip ratio (WHR). These results are consistant with the information that not only obesity but more importantly the distribution of the body fat, mostly the upper body fat influence the glucose metabolism and are independent risk factor for developing T2 DM (Kopleman, 2000). Rajrajeswari et al. (2011) reported that TNF- $\alpha$ had a positive association with WHR and serum insulin (Ashfaq and Farasat, 2017).

In our study high values of thrombomodulin were observed in IGT and diabetic group as compared to 
control group. In multistep regression thrombomodulin also showed an association with TNF- $\alpha$ in diabetic group. In the inflammatory processes the activated neutrophils exercise a proteolytic activity and cause the detachment of thrombomodulin from the endothelial cells thus raising its concentration in the blood. Soluble thrombomodulin is traditionally thought to serve as a marker of endothelial cell damage (Califano et al., 2000). High levels of thrombomodulin in diabetic subjects indicate the higher vascular damage. TNF- $\alpha$ induces the production of ROS and decreases the bioavailability of nitrogen oxide (NO) causing vascular dysfunction and vascular damage (Picchi et al., 2006; Goodwin et al., 2007). Vascular damage is reflected in the higher levels of thrombomodulin

\section{CONCLUSION}

This study shows significantly elevated serum levels of TNF- $\alpha$ and thrombomodulin along with 2.44 fold over expression of TNF- $\alpha$ gene in IGT and 4.5 fold over expression in diabetic subjects when compared with control subjects. This study underscores the activation and accelerated expression of TNF- $\alpha$ in PBMC in hyperglycemic conditions causing vascular inflammation.

\section{ACKNOWLEDGMENTS}

We sincerely thank diabetic patients for their help in the clinical evaluation and data collection. We acknowledge the financial support of HEC (Ref \# 20_1650/R \& D/09(2809)) to carry out our research work with full satisfaction.

\section{Statement of conflict of interest}

Authors have declared no conflict of interest.

\section{REFERENCES}

Califano, F., Giovanniello, T., Pantone, P., Campana, E., Parlapiano, C., Alegiani, F., Vincentelli, G.M. and Turchetti, P., 2000. Clinical importance of thrombomodulin serum levels. Europ. Rev. med. Pharmacol. Sci., 4: 59-66.

Ashfaq, F, and Farasat, T., 2017. Association of serum resistin with Indices of obesity in young Pakistani subjects. Pakistan J.Zool., 49: 1587-1593.

Cardellini, M., Andreozzi, F., Laratta, E., Marini, M.A., Lauro, R., Hribal, M.L., Perticone, F. and Sesti, G., 2007. Plasma IL-6 levels are increased in subjects with impaired glucose tolerance but not in those with impaired fasting glucose in a cohort of Italian Caucasians. Diabet. Metab. Res., 23: 141-145. https://doi.org/10.1002/dmrr.679
Coughlan, M.T., Oliva, K., Georgiu, H.M., Permezel, J.M. and Rice, G.E., 2001. Glucose induced release of tumour necrosis factor-alpha from human placental tissue in gestational diabetes mellitus. Diabet. Med., 18: 921-927. https://doi.org/10.1046/ j.1464-5491.2001.00614.x

Curtis, M., Steyers, H.I. and Miller, F.J., 2014. Endothelial dysfunction in chronic inflammatory diseases. Int. J. mol. Sci., 15: 11324-11349. https:// doi.org/10.3390/ijms150711324

Deepa, R., Velmurugan, K., Arvind, K., Sivaram, P., Sientay, C., Uday, S. and Mohan, V., 2006. Serum levels of interleukin 6, C-reactive protein, vascular cell adhesion molecule 1 , and monocyte chemotactic protein 1 in relation to insulin resistance and glucose intolerance - the Chennai Urban Rural Epidemiology Study (CURES). Metabolism, 55: 1232-1238. https://doi. org/10.1016/j.metabol.2006.05.008

De Martin, R., Hoeth, M., Hofer-Warbinek, R. and Schmid, J.A., 2000. The transcription factor NF$\mathrm{kB}$ and the regulation of vascular cell function. Arteriosclerosis Thrombosis and Vascular Biol., 20: E83-E88. https://doi.org/10.1161/01.ATV.20.11. e83

Gacka, M., Dobosz, T., Szymaniec, S., BednarskaChabowska, D., Adamiec, R. and SadakierskaChudy, A., 2010. Proinflammatory and atherogenic activity of monocytes in type 2 diabetes. $J$. Diabet. Compl., 24: 1-8. https://doi.org/10.1016/j. jdiacomp.2008.07.001

Gokulakrishnan, K., Tulasi, M., Monickaraj, F., Mohan, V. and Balasubramanayam, M., 2009. Subclinical inflammation/oxidation as revealed by altered gene expression profile in subjects with impaired glucose tolerance and type 2 diabetes patients. Mol. cell. Biochem., 324: 173-181. https://doi.org/10.1007/ s11010-008-9996-X

Goodwin, B.L., Pendleton, L.T., Levy, M.M., Solomon, L.P. and Fichler, D.C., 2007. Tumor necrosis factorreduces argininosuccinate symthase expression and nitric oxide production in aorticendothelial cells. Am. J. Physiol. Heart Circulat. Physiol., 293: 11151121. https://doi.org/10.1152/ajpheart.01100.2006

Gupta, A., Ten, S. and Anhalt, H., 2005. Serum levels of soluble TNF- $\alpha$ receptor 2 are linked to insulin resistance and glucose tolerance in children. Pediat. Endocrinol. Metab., 18: 75-82.

Hartmann, J. and Frishman, WH., 2014. Inflammation and Atherosclerosis: a review of the role of interleukin- 6 in the development of atherosclerosis and the potential for targeted drug therapy. Cardiol. Rev., 22: 147-151. https://doi.org/10.1097/ 
CRD.0000000000000021

Hossain, M., Faruque, M.O., Kabir, G., Hassan, N., Sikdar, D., Nahar, Q. and Ali, L., 2010. Association of serum TNF- $\alpha$ and IL- 6 with insulin secretion and insulin resistance in IFG and IGT subjects in a Bangladeshi population. Int. J. Diabet. Mellitus, 2: 165-168. https://doi.org/10.1016/j. ijdm.2010.08.004

Hotamsligil, G.S. and Spiegelman, B.M., 1994. Tumor necrosis factor alpha: A key component of the obesity-diabetes link. Diabetes, 43: 1271-1278. https://doi.org/10.2337/diab.43.11.1271

Kopelman, P.G., 2000. Obesity as a medical problem. Nature, 404: 635-643.

Mangge, H., Hubmann, H., Pilz, S., Schauenstein, K., Renner, W. and Marz, W., 2004. Beyond cholesterolinflammatory cytokines, the key mediators in atherosclerosis. Clin. Chem. Lab. Med., 42: 467474. https://doi.org/10.1515/CCLM.2004.081

Martin, D., Michael, W.J., Bohme, Galle, P., Stremmel, W., 2002. Kinetics of Thrombomodulin release and endothelial cells injury by neutrophil derived processes and oxygen radical. Immunology, 107: 340-349. https://doi.org/10.1046/j.13652567.2002.01469.x

Micheal, W.J., Bohme., Galle, P. and Stremmel, W., 2002. Kinetics of thrombomodulin releaase and endothelial cells injury by neutrophil derived processes and oxygen radical. Immunology, 107: 340-349.

Mishima, Y., Kuyama, A., Tada, Takashi, K., Ishioka, Kibata, M., 2001. Relationship between TNF-alpha and Insulin resistance in obese men with type 2 diabetes mellitus. Diabet. Res. Clin.l Pract., 52: 119-123.

Mirza, S., Hussain, M., Mathews, C., Martinez, P., Pino, P., Gay, J.L., Rentfro, A., McCormick, J.B. and Fisher-Hoch, S.P., 2012. Type-2 diabetes is associated with elevated levels of TNF-alpha, IL-6 and adiponectin and low levels of leptin in a population of Mexican American: A cross sectional study. Cytokine, 57: 136-142. https://doi. org/10.1016/j.cyto.2011.09.029

Morohoshi, M., Fujisawa, K., Uchimura, I. and Numano, F., 1996. Glucose-dependent interleukin-6 and tumor necrosis factor production by human peripheral blood monocytes in vitro. Diabetes, $\mathbf{4 5}$ : 954-959. https://doi.org/10.2337/diabetes.45.7.954

Ohlin, A.K., Larsson, K. and Hansson, M., 2005. Soluble thrombomodulin activity and soluble thrombomodulin antigen in plasma. J. Thrombosis Haemostasis, 3: 976-982. https://doi.org/10.1111/ j.1538-7836.2005.01267.x
Picchi, A., Gao, X. and Belmadani, S., 2006. Tumor necrosis factor- $\alpha$ induces endothelial dysfunction in the prediabetic metabolic syndrome. Circulat. Res., 99: 69-77. https://doi.org/10.1161/01. RES.0000229685.37402.80

Pickup, J.C., Chusney, G.C., Thomas, S.M. and Burt, D., 2000. Plasma interleukin-6, tumor necrosis factor alpha and blood cytokine production in type 2 diabetes. Life Sci., 67: 291-300. https://doi. org/10.1016/S0024-3205(00)00622-6

Rajarajeswari, D., Ramalingam, K. and Naidu, J.N., 2011. Tumor necrosis factor- alpha in the development of insulin resistance in type 2 diabetes mellitus. Int. J. appl. Biol. Pharmaceut. Technol., 2: $55-60$.

Schmidt, M.I., Duncan, B.B., Sharrett, A.R., Lindberg, G., Savage, P.J., Offenbacher, S., Azambuja, M.I., Tracey, R.P. and Heiss, G., 1999. Markers of inflammation and prediction of diabetes mellitus in adults (atherosclerosis risk in communities study): A cohort study. Lancet, 353: 1649-1652. https://doi. org/10.1016/S0140-6736(99)01046-6

Simms, D., Cizdziel, P.E. and Chomczynski, P., 1993. Trizol: A new reagent for optimal single- step isolation of RNA. Focus, 15: 499.

Togashi, N., Ura, N., Murakami, H. and Shimmoto, K., 2002. Effect of TNF- $\alpha$ converting enzyme inhibitor on insulin resistance in fructose fed rats. Hypertension, 39: 578-580. https://doi.org/10.1161/ hy0202.103290

Temelkova-Kurktschiev, T., Siegert, G., Bergmann, S., Henkel, E., Koehler, C., Jaross, W. and Hanefield, M., 2002. Subclinical inflammation is strongly related to insulin resistance but not insulin secretion in a high risk population for diabetes. Metabolism, 51: 743-749. https://doi.org/10.1053/ meta.2002.32804

Tuomisto, K., Jousilahti, P., Sundvall, J., Pajunen, P. and Salomaa, V., 2006. C-reactive protein, interleukin-6 and tumor necrosis factor alpha as predictors of incident coronary and cardiovascular events and total mortality.A population-based, prospective study. Thrombosis Haemostasis, 95: 511-518. https://doi.org/10.1160/TH05-08-0571

Navarro-Gonzalez, J., Mora-Fernandez, C., GomezChinchon, M., Muros, M., Herrera, H. and Garcia, J., 2009. Serum and gene expression profile of Tumor necrosis factor- $\alpha$ and interleukin- 6 in Hypertensive diabetic patients: Effect of amlodipine administration. Int. J. Immunopathol. Pharmacol., 22: 51-59.

Ye, J., Wang, L., Zhang, X., Tantishaiyakul, V. and Rojanasakul, Y., 2003. Inhibition of TNF-alpha 
gene expression and bioactivity by site-specific transcription factor-binding oligonucleotides. Am. J. Physiol. Lung cell. mol. Physiol., 284: 386-394. https://doi.org/10.1152/ajplung.00134.2002

Williams, M.D. and Nadler, J.L., 2007. Inflammatory mechanisms of diabetic complications. Curr. Diabet. Rep., 7: 242-248. https://doi.org/10.1007/ s11892-007-0038-y

Zhang, H., Park, Y., Junxi, W.U., Chen, X.P., Lee, S., Yang, J., Kevin, C., Sperger, D. and Zhang, C., 2009. Role of TNF- $\alpha$ in vascular dysfunction. Clin. Sci., 116: 219-230. https://doi.org/10.1042/ CS20080196 